\title{
APLICAÇÃO DE CÁLCULO DIFERENCIAL NA OTIMIZAÇÃO DE ÁREAS E VOLUMES COM USO DE MATERIAIS CONCRETOS MANIPULÁVEIS
}

\section{APPLICATION OF DIFFERENTIAL CALCULUS IN THE OPTIMIZATION OF AREAS AND VOLUMES WITH THE USE OF MANIPULABLE CONCRETE MATERIALS}

\author{
Poliana Pereira Lopes ${ }^{1}$ \\ Instituto Federal de Mato Grosso (IFMT) - Campus Confresa \\ Victor Pereira Machado ${ }^{2}$ \\ Instituto Federal de Mato Grosso (IFMT) - Campus Confresa \\ Thiago Beirigo Lopes ${ }^{3}$ \\ Instituto Federal de Mato Grosso (IFMT) - Campus Confresa
}

\begin{abstract}
Resumo
Com base na experiência docente e discente dos autores nas aulas de Cálculo Diferencial e estudos realizados por outros pesquisadores, percebeu-se que o ensino de matemática em cursos superiores ainda carece de uma eminente reestruturação de seus métodos e metodologias para as práticas pedagógicas. Surge, então, a questão norteadora dessa pesquisa: O estudo com material concreto manipulável pode auxiliar no aprendizado de otimização? Frente a essa questão, a pesquisa exploratória realizada teve o objetivo de analisar se o estudo de otimização de áreas e volumes com a confecção de material concreto manipulável auxilia na compreensão do conceito e da aplicação desse conteúdo. Visto que a otimização é um dos conteúdos estudados dentro do Cálculo Diferencial. Para cumprir tal objetivo, foi realizado um minicurso durante a I Jornada de Ensino, Pesquisa e Extensão (JENPEX) do Instituto Federal de Mato Grosso (IFMT) - Campus Confresa. Para a realização do minicurso foram utilizadas apostilas e projetor de imagem para exploração das atividades planejadas. As atividades foram subsidiadas de modo a aguçar a criatividade dos participantes com a utilização de materiais manipuláveis. Por fim, considera-se que o objetivo estabelecido por essa investigação foi atingido, pois as atividades desenvolvidas com a utilização de materiais concretos manipuláveis possibilitaram aos estudantes maior interação entre teoria e prática devido conseguirem, por meio da confecção e manuseio desses materiais, construir conceitos sobre otimização e analisá-los.
\end{abstract}

Palavras-chave: Ensino de Cálculo; Otimização; Máximos e mínimos; Materiais concretos manipuláveis.

\footnotetext{
${ }^{1}$ Endereço eletrônico: poliana.cfs1998@gmail.com

${ }^{2}$ Endereço eletrônico: victorpereiramt@gmail.com

${ }^{3}$ Endereço eletrônico: thiagobeirigolopes@yahoo.com.br
} 


\begin{abstract}
Based on the authors' teaching and student experience in Differential Calculus classes and studies by other researchers, it was noticed that mathematics teaching in higher education still needs an imminent restructuring of its methods and methodologies for pedagogical practices. Then, the guiding question of this research arises: Can the study with manipulable concrete material help in the learning of optimization? In view of this issue, the exploratory research carried out aimed to analyze whether the study of optimization of areas and volumes with the manufacture of manipulable concrete material helps in understanding the concept and application of this content. Since optimization is one of the contents studied within Differential Calculus. To fulfill this objective, a short course was held during the First Day of Teaching, Research and Extension (JENPEX) of the Federal Institute of Mato Grosso (IFMT) - Campus Confresa. For the short course were used handouts and image projector to explore the planned activities. The activities were subsidized in order to sharpen the participants' creativity with the use of manipulable materials. Finally, it is considered that the objective established by this investigation was achieved, since the activities developed with the use of manipulable concrete materials allowed the students greater interaction between theory and practice because they were able to construct concepts through the preparation and handling of these materials. about optimization and analyze them.
\end{abstract}

Keywords: Calculus Teaching; Optimization; Highs and lows; Handling concrete materials.

\title{
Considerações iniciais
}

Nas instituições de ensino, sejam elas do nível básico ou superior, predomina um modelo de aula cartesiano, linear e reducionista, no qual o estudante é mero receptor de informações apresentadas pelo professor. Nesse papel, resta ao estudante limitar-se ao desenvolvimento da memorização e reprodução mecânica do que é ensinado (LOPES; SANTOS, 2016). Em uma tentativa de sintetizar, é perceptível que os estudantes ainda estão limitados a estudar no curto espaço de suas mesas e cadeiras, sendo-lhes exigidas apenas as habilidades de memorização e reprodução mecânica.

Contudo, esse modelo de ensino tem se mostrado ineficaz para a construção do conhecimento do estudante. Isso pode ser demonstrado pelos altos índices de reprovação que geram como consequência, um grande número de evasões. Segundo Lopes e Santos (2016), sob a perspectiva da formação multidisciplinar do estudante, uma abordagem tradicional de ensino também não se mostra suficiente por não colaborar com o pleno desenvolvimento dos aspectos exigidos pela sociedade contemporânea em relação aos futuros profissionais: criatividade, raciocínio crítico, iniciativa, entre outras. Ainda segundo os autores, “[...] os valores da educação tradicional baseados no saber do professor, se fazem opostos aos valores emergentes da 
sociedade que começa a tornar legítimo o saber, o saber fazer e o saber ser" (LOPES; SANTOS, 2016, p. 1).

Sobre esse modelo de ensino supracitado e sua afinidade com o processo de ensino, é pertinente o que dizem Gravina e Santarosa (1999) ao afirmarem que no processo de pesquisa vivenciado pelos estudantes destaca-se esse método como inadequado para essa abordagem. Trazendo a discussão para o ensino de matemática, o conhecimento pode ser constituído a partir do processo de uma constante investigação e exploração, em que a formalização é a conclusão deste trabalho, que finaliza na escrita formal e organiza os resultados matemáticos obtidos.

Apesar de sua grande importância histórica e atual como conhecimento, o ensino do cálculo diferencial e integral em muitos casos ainda sustenta sua estrutura original, sendo vista como uma das disciplinas em que se apresenta as maiores dificuldades de aprendizado quando do ingresso no nível superior (CAVASOTTO, 2010). É importante ressaltar que o cálculo diferencial e integral consiste em ser uma das disciplinas mais tradicionais nos cursos de Ciências Exatas e base referencial para o desenvolvimento científico e tecnológico. Isso desde que foi vislumbrado a mais de trezentos anos por Isaac Newton (1646-1727) na Inglaterra e Gottfried Wilhelm Leibniz (1646-1716) na Alemanha (BOYER, 1992).

Diante do exposto, percebe-se que o ensino de Cálculo em cursos superiores ainda carece de uma eminente reestruturação de seus métodos e metodologias para a prática pedagógica. Emerge então a questão norteadora dessa pesquisa: O estudo com material manipulável concreto pode auxiliar no aprendizado sobre otimização?

Frente a essa questão, foi elaborada uma pesquisa exploratória que teve como instrumentos questionários e atividades elaboradas com uso de material concreto. Seu objetivo foi o de analisar se o estudo de otimização de áreas e volumes com a confecção de material concreto manipulável auxilia na compreensão do conceito e da aplicação desse conteúdo. Para cumprir tal objetivo, foi realizado um minicurso durante a I Jornada de Ensino, Pesquisa e Extensão (JENPEX) do Instituto Federal de Mato Grosso (IFMT) - Campus Confresa. Para a realização do minicurso foram utilizadas apostilas e equipamentos eletrônicos para exploração das atividades planejadas. As atividades foram subsidiadas de modo a aguçar a criatividade dos participantes com a utilização de materiais concretos manipuláveis. 


\section{Materiais concretos manipuláveis e a criatividade para o ensino de otimização}

Dentre os conteúdos importantes, presente em quase todos os cursos de Cálculo, está a otimização. Entretanto, na maioria das vezes, o seu ensino é feito nos moldes do modelo já questionado nesse texto. Em contraposição a esse modelo, o uso de materiais manipuláveis surge como alternativa interessante por aguçarem a criatividade do estudante na busca por soluções dos problemas. O estudo de cálculo diferencial que comumente é realizado somente de modo informativo, sem qualquer interação entre quem é informado e quem informa (ROCHA, 2013). No entanto, esse conteúdo nasce de uma necessidade prática e esse modelo de ensino vem em sentido contrário ao ambiente de sua concepção.

O estudo sobre otimização é relevante por trazer a possibilidade de aplicação prática de um conteúdo que normalmente não extrapolava os limites do livro, caderno ou lousa e se torne algo concreto ao estudante. Segundo Mello e Mello (2003), otimizar é uma atividade que ocupa grande parte da vida pessoal ou profissional. Pode-se maximizar os gastos em relação à receita recebida, gastos com bens e serviços obtidos com o salário, o lucro para a empresa ou comércio com os recursos disponíveis ou, ainda, a redução de custos operacionais.

De acordo com Mello e Mello (2003), a otimização é um tema recorrente nos cursos que possuem em sua ementa o cálculo diferencial. Ainda segundo os autores, apesar da otimização ser uma das principais características desse conteúdo, o seu ensino é quase sempre negligenciado pela hipotética necessidade de resolver uma infinidade de exercícios. Os problemas de máximos e mínimos são frequentemente abordados e resolvidos de modo mecânico, sem explorar o potencial que eles proporcionam para instigar o interesse do estudante e servir de motivação para o estudo de disciplinas posteriores.

Em sua investigação, Rocha (2013) defendeu que os estudos de otimização devem iniciar já no ensino médio, de modo que apresente alguns métodos algébricos acessíveis a esse estudante para resolução de problemas simples de otimização. Visto que nesse nível de ensino não é comum o estudo de cálculo diferencial, mesmo que alguns pesquisadores como Ávila (1991), Silva e Sousa (2014) defendam seu ensino nesse nível, o foco principal foram as funções quadráticas. Esses últimos autores citados 
indicam que a aplicação dos métodos é exemplificada por meio de variadas situações problema, elencadas de modo a mostrar uma ampla e significativa diversidade que permite a utilização dos métodos desenvolvidos.

Os estudos de Azevedo (2015) tiveram o objetivo de mostrar algumas aplicações matemáticas simples e detalhadas, por meio de alguns problemas de otimização, em que o estudante percebesse e compreendesse o mundo matemático que o cerca. Então foram realizados estudos, a partir de conhecimentos sobre funções trabalhadas no ensino médio, para construir definições, teoremas e proposições a respeito da otimização de modo a proporcionar ferramentas capazes de solucionar problemas de matemática, física e economia.

Cabral (2015) realizou uma investigação cujo objetivo foi compreender como os estudantes resolvem problemas de otimização nos estudos sobre derivada de uma função, com atenção às estratégias adotadas, aos conhecimentos que revelam em relação à derivada de uma função e as principais dificuldades apresentadas. A autora concluiu que os estudantes recorrem principalmente à relação entre o sinal da função derivada, sentido de variação e extremos relativos da função original para resolver problemas de otimização. Nos primeiros problemas aplicados, os estudantes aplicaram os procedimentos matemáticos de modo mecânico, ou seja, sem considerar a situação problema apresentada. O que ocasionou por muitas vezes que terminassem os cálculos sem apresentar uma resposta aceitável para o problema proposto.

Parte dos estudos de Pinto (2014) envolveu a aplicação de atividades que envolviam o estudo de otimização por meio da derivada. A pesquisa teve o objetivo de compreender as possíveis contribuições de discussões realizadas por grupos de estudantes referentes aos estudos sobre funções e suas derivadas por meio de programas digitais dinâmicos para o desenvolvimento do pensamento matemático. Como resultado pode-se destacar a ressignificação da aplicação de derivada em otimização a partir das interações ocorridas durante as atividades desenvolvidas.

Nesse levantamento realizado sobre estudos anteriores que discutiam de forma direta ou indireta atividades que envolveram otimização, não foi encontrado algo que desvelasse sobre a criatividade como componente no processo. Segundo Nakano (2011, p. 311) a criatividade é um "[...] potencial a ser desenvolvido em todos os indivíduos e, 
portanto, uma característica passível de ser incentivada e treinada, cujos benefícios têm sido destacados principalmente no ambiente escolar".

Há algum tempo a criatividade tem sido evidenciada no processo de ensinoaprendizagem, há mais de duas décadas Alencar (1986, p. 15) já evidenciava a necessidade de perceber a criatividade como agente ativo no processo de ensino. Em suas palavras, "[...] é necessário ressaltar, pois, que o desenvolvimento e manifestação da criatividade não depende somente dos esforços do próprio indivíduo", ou seja, os fatores intrapessoais ou interpessoais, os fatores do próprio indivíduo ou de natureza social poderão propiciar ou bloquear o processo criativo.

Demo (1993) ressalta que o professor precisa ter a capacidade de desenvolver no estudante a habilidade de criatividade, tornando suas aulas desafiadoras, provocadoras e instigadoras. No entanto, é necessário que esse professor expresse-se com destreza; domine conhecimentos e informações estratégicas para o processo de transformação da realidade atual.

Segundo D'Ambrósio (2012), é importante que o professor de matemática consiga ter compreensão do que vem a ser a matemática, do que constitui a atividade matemática e o que caracteriza um ambiente favorável para a aprendizagem da matemática. Tudo isso, concomitantemente à utilização de estratégias de ensino que promovam a criatividade, possivelmente deve contribuir para garantir a melhora nos níveis de motivação para os estudantes estarem interessados em aprender matemática. Ainda, Otaviano, Alencar e Fukuda (2012, p. 67) indicam que os professores precisam estar aptos a "[...] compreender melhor a relação e entre práticas pedagógicas utilizadas pelo professor e motivação do aluno e ainda a relação entre motivação do aluno e seu rendimento acadêmico em matemática".

Uma alternativa para explorar a criatividade dos estudantes é a utilização de materiais concretos que podem ser manipulados durante o processo de ensino de matemática. Segundo Alves (2006), os instrumentos utilizados no ensino devem propiciar condições agradáveis e favoráveis para o ensino de matemática. Pois o estudante é motivado a trabalhar tendo por base o material concreto, descobrindo, reinventando e não só recebendo informações.

No entanto, o modo de abordagem com material concreto necessita de atenção especia, Carvalho (2009) defende uma ação centrada não no objeto, mas nas operações 
que se realizam sobre ele, pois indica que durante a manipulação do material didático a ênfase não deve estar nos objetos em si e sim sobre as operações que com eles são realizadas. $\mathrm{O}$ autor ainda diz não concordar com as propostas pedagógicas que o material didático tem a mera função ilustrativa, pois desse modo o estudante permanece um agente passivo que recebe instrução proposta pelo professor com respostas do tipo sim ou não.

Em corroboração ao anterior, Serrazina (1990) destaca que todo tipo de material deve ser utilizado de forma cuidadosa. Indica que o mais relevante não é o material por si só, mas a experiência que deve ele proporcionar quando manipulado pelo estudante, pois a utilização dos materiais, por si só, não significa que há a possibilidade de uma aprendizagem efetiva. Desse modo, é destacado o papel fundamental do professor no planejamento relativo aos materiais didáticos a serem utilizados durante a aula.

O manuseio de materiais concretos pode permitir aos estudantes obterem experiências físicas à medida que efetuam contato direto com os materiais, seja por meio de medições, registros ou comparação com outros materiais de mesma natureza. Permite-lhes também ter experiências lógicas por meio de diversificados modelos de representação que podem tornar possíveis as abstrações empíricas e abstrações reflexivas, com possibilidade de evoluir para generalizações mais complexas.

Em seus estudos Rodrigues e Gazire (2012) concluíram que os materiais manipuláveis podem ser importantes auxiliares na aprendizagem dos estudantes. Nesse sentido, utilizar os materiais manipuláveis em sala de aula pressupõe um exercício de prática reflexiva para o professor e que este possa utilizá-los de maneira correta, com vistas a tornar assim a aprendizagem dos estudantes mais efetiva e prazerosa.

De acordo com Botas e Moreira (2013), as diversas terminologias desse tipo de material didático apresentadas na literatura, levam a constatar que há o uso de 'material manipulável' e 'material concreto'. No entanto, ainda segundo as autoras, é de notar que essas as designações são distintas, apesar de se englobarem e, às vezes, se confundirem. Uma vez que, amparando-se nas concepções de Alves e Morais (2006), entende-se por material manipulável aquele que o estudante pode interagir com ele, em que tem abrangência nos materiais digitais, e por material concreto aquele que é possível ao estudante ver e tocar. Diante disso, para esse estudo foi adotada a caracterização dos materiais didáticos como sendo 'materiais concretos manipuláveis', em que permitem o 
estudante a manipular e tocar tais materiais. Pois vai ao encontro com o exposto por Carvalho (2009) e Serrazina (1990) que possibilita ao professor desenvolver um ensino focado no estudante e na sala de aula. Ainda estes materiais auxiliam na aprendizagem por permitir que os estudantes manipulem ou construam o próprio material assim desenvolvendo nos estudantes uma atitude ativa diante da aprendizagem da matemática.

\section{Procedimentos metodológicos}

A pesquisa qualitativa foi realizada durante o segundo semestre de 2017 , no IFMT - Campus Confresa. Trata-se da preparação e realização do minicurso "Utilização de derivadas para otimização de áreas e volumes", que foi ministrado durante o evento I JENPEX na instituição supracitada. Em momento anterior à realização do minicurso. $\mathrm{O}$ minicurso contou com 11 participantes, sendo 10 estudantes matriculados nos cursos superiores da instituição e 1 professor da área de Química que faz parte do quadro de professores do referido Campus. A duração do minicurso foi de 3 horas.

É importante destacar que havia pré-requisitos que os estudantes deveriam atender para poderem participar do minicurso. Os estudantes deveriam estar devidamente matriculados no ensino superior no IFMT - Campus Confresa e deveriam ter cursado a disciplina Cálculo 1, que é a disciplina que possui máximos e mínimos na ementa dos cursos superiores ofertados. Esses pré-requisitos foram estabelecidos devido ao conteúdo abordado necessitar de um conjunto conhecimentos prévios, que é importante para que os participantes possam compreender a proposta do minicurso com êxito.

Essa atividade é parte integrante do projeto de pesquisa "Elaboração de propostas pedagógicas no ensino e aprendizagem de cálculo diferencial e integral para contrapor o alto índice de insucesso no IFMT” que foi aprovado no Edital 036/2017 IFMT/FAPEMAT. Participam como executores das atividades do projeto, o docente coordenador, dois docentes colaboradores internos e os dois estudantes bolsistas do projeto. No entanto, para a realização desse minicurso, estiveram presentes $\mathrm{o}$ coordenador e os dois estudantes bolsistas.

Foram realizados levantamentos de questões nos livros do Guidorizzi (2013), Ayres e Mendelson (2013) e Munem e Foulis (1982), que estavam disponíveis para consulta na biblioteca institucional, para elaboração de uma apostila que teve o 
propósito de facilitar o acompanhamento dos participantes em relação às atividades desenvolvidas no minicurso.

Após o levantamento, as considerações mais relevantes sobre o tema (como definição e conceitos) e mais três questões sobre otimização de áreas e volumes foram reunidos em um único material didático, em forma de apostila.

O minicurso foi dividido em quatro partes, em que a primeira parte diz respeito à apresentação dos objetivos, das atividades propostas e da assinatura do Termo de Consentimento Livre Esclarecido (TCLE). A segunda parte foi teórica e com resoluções de questões para que os participantes dos minicurso pudessem relembrar como aplicar a Derivada. A terceira parte foi prática, em que os participantes puderam aplicar a Derivada para otimização e trabalharem com material manipulável. E, por fim, a quarta parte foi de avaliação das atividades e do minicurso por meio do questionário a ser respondido pelos participantes.

$\mathrm{Na}$ primeira parte foram apresentadas as etapas das atividades e solicitado a todos que lessem e assinassem o TCLE, que é um documento de permissão em relação às informações obtidas no minicurso para a possibilidade de que fossem publicadas. Esse documento esclarece que estão participando do projeto de pesquisa e que não haverá bônus ou ônus. $\mathrm{O}$ documento informa também que os participantes não serão identificados em algum momento. Além disso, que não são obrigados a participar da pesquisa e as informações apenas serão publicadas com o consentimento dos participantes ao assinarem.

Para auxiliar na segunda parte, a apostila foi constituída da seguinte maneira:

Introdução: Com conceitos de derivada, suas propriedades e suas técnicas de derivação. Também uma breve contextualização sobre otimização de áreas e volumes.

Situação Problema 1 e sua resolução (exercício que envolve uma situação real sobre otimização de área): "Tem-se material para construir 50 metros de cerca de um galinheiro de formato retangular. Sabendo que se pretende ter a área máxima, quais devem ser as dimensões desse galinheiro? E se for utilizado um muro para ser um dos lados desse galinheiro?" 
Situação Problema 2 e sua resolução (exercício que envolve uma situação real sobre otimização de volume): Deseja-se construir uma piscina quadrada que comporte $64 \mathrm{~m}^{3}$ de água, que corresponde a 64.000 litros de água. Então qual deve ser o tamanho de cada dimensão dessa piscina sabendo que se deseja gastar o mínimo possível de material?

Situação Problema 3 e sua resolução (exercício que envolve uma situação sobre otimização de volume e foi base para a realização da segunda parte do minicurso): Tem-se uma cartolina com dimensões de $40 \mathrm{~cm}$ x $50 \mathrm{~cm}$. Necessita-se de cortar as pontas de modo que se consiga construir uma caixa sem tampa com o maior volume possível.

Um dos bolsistas do projeto apresentou a definição de máximos e mínimos, e em seguida resolveu no quadro as questões presentes na apostila com apoio de um projetor de imagens. É importante destacar, que os participantes poderiam interromper a apresentação e resolução dos problemas a qualquer momento que surgissem dúvidas. Assim, houve algumas interrupções durante a apresentação para que houvesse explicação sobre as dúvidas que surgiram.

Para a realização do minicurso foram utilizados os seguintes materiais: projetor de imagens para exposição de slides, notebook, papel sulfite para impressão das apostilas, cartolinas para construção das caixas (parte prática do minicurso), régua, tesoura e cola.

Foi organizada previamente uma sala de aula do IFMT para a realização da atividade, onde havia mesas redondas e cadeiras para acomodar os participantes. Ao chegarem na sala, os participantes se acomodavam na mesa conforme sua preferência e, dessa forma, acabaram se dividindo em 3 grupos (Grupo 1, Grupo 2 e Grupo 3), com quantidade de integrantes distintas. O Grupo 1 ficou com 3 integrantes, o Grupo 2 ficou com 4 integrantes e o Grupo 3 também com 4 integrantes. Desse modo, no total, foram 11 estudantes que participaram do minicurso, e estes estão identificados nesta pesquisa por $\mathrm{P}$ (participante) seguidos por um número (P1, P2, .., P11).

A terceira parte do minicurso consistiu em atividades práticas envolvendo aplicação de derivadas ao que tange as otimizações. A atividade foi desenvolvida pelos participantes, que construíram caixinhas de maior volume possível com papel cartolina. Basicamente, os participantes realizaram na prática a situação problema da questão 3, 
com cartolinas de diferentes dimensões. Os estudantes realizaram os cálculos e, a partir dos resultados, construíram as caixas com o maior volume possível.

Foram entregues aos estudantes, papeis A4 para realização dos cálculos, cartolinas, lápis, régua, tesoura, e cola para serem utilizadas na confecção das caixinhas sem tampa. Mais especificamente, cada grupo recebeu 3 cartolinas com dimensões diferentes. Após a entrega dos materiais, os participantes foram instruídos a aferir as dimensões das cartolinas, e anotar para a realização dos cálculos. Com os cálculos realizados, os participantes foram orientados a confeccionar as caixas sem tampa.

É importante destacar que a primeira cartolina utilizada nos três grupos como exemplo possuía a mesma dimensão, visando facilitar a verificação junto com os responsáveis pelo minicurso. As outras duas cartolinas entregues aos três grupos possuíam tamanhos variados, permitindo aos participantes uma nova realização do processo de confecção, com cartolinas diferentes, promovendo uma nova experiência. Lembrando que todas essas atividades foram realizadas com o auxílio dos três executores do minicurso.

Para a quarta parte, foi elaborado o questionário para ser aplicado aos participantes do minicurso. Esse questionário foi elaborado com intuito de coletar dados para saber sobre os estudos anteriores em relação à derivada e sobre a opinião em relação ao minicurso ministrado. A seguir estão dispostas as questões presentes no questionário:

1. Você já teve aulas práticas que envolvam aplicações de Derivadas?

Foi elaborada com objetivo de identificar se os participantes tiveram aulas práticas sobre derivadas, além de obter indícios se essas aulas podem ter relação com o alto índice de insucesso do IFMT - Campus Confresa em cálculo diferencial.

2. Você já havia estudado sobre aplicações de derivadas em máximos e mínimos?

Esteve no questionário visando constatar se os estudantes têm ou não familiaridade com o contexto de máximos e mínimos.

3. O minicurso "Utilização de derivadas para otimização de áreas e volumes" the ajudou a compreender esse tipo de aplicação?

É mais voltada para a finalidade do minicurso, visando perceber se o método utilizado auxiliou os estudantes a compreender o tema. 
4. Se houvesse mais iniciativas como o deste minicurso durante as aulas de cálculo diferencial, você acredita que o processo de ensino e aprendizagem desse conteúdo seria facilitado?

Busca a opinião dos participantes em relação ao uso do método frequentemente, ou seja, o que os participantes pensam sobre utilizar este método como recurso em sala de aula.

\section{Como você avalia o minicurso realizado?}

Essa questão foi inserida no questionário por acreditar que é importante ter uma devolutiva dos envolvidos na pesquisa. Assim, para que haja a possibilidade de reflexão em relação às atividades propostas e executadas em busca do aprimoramento.

Algumas das questões foram elaboradas de modo a serem respondidas com um sim ou não. No entanto, o intuito dessa particularidade foi que se houvesse respostas com explicações, elas seriam espontâneas e não realizadas somente para cumprir o solicitado.

\section{Resultados e reflexões}

Para apresentação dos resultados, essa seção está dividida em três situações. A primeira trata das aulas com o intuito de realizar uma revisita do estudantes aos estudos de derivada e, mais especificamente, otimização. A segunda situação é em relação ao planejamento e confecção das caixinhas sem tampa durante o minicurso, em que serão descritas as estratégias dos estudantes para resolução da situação problema que foram possíveis serem observadas e as estratégias que utilizaram para aplicar tais resultados na confecção das caixinhas. Por fim, a terceira aborda a análise de cada uma das questões respondidas pelos participantes com a aplicação do questionário.

\section{Revisitando derivadas e otimização}

Com os participantes em posse de suas apostilas, um dos ministrantes fez uma breve explanação sobre as derivadas e relembrando seus conceitos, propriedades e técnicas de derivação. Em que o estudante poderia interromper a qualquer momento e socializar se surgisse alguma dúvida. Em seguida, foram relembrados os conceitos de máximos e mínimos com posterior estudo sobre otimização e sua importância em problemas concretos. 
Após esse momento, o ministrante continuou a explanação resolvendo na lousa os cálculos de cada uma das 3 situações problemas contidas na apostila, com apoio do projetos de imagens para mostrar mostrando alguns exemplos de questões que envolviam otimização. Enquanto isso, os demais ministrantes auxiliavam os grupos de participantes quando surgiam alguma dúvida.

\section{Confecção das caixinhas}

Na primeira proposta para confecção de caixinha, as medidas de cada cartolina entregue a cada grupo eram as mesmas. Isso foi planejado por supor que os estudantes poderiam ter dificuldade na primeira resolução e confecção das caixinhas. No entanto, somente um grupo solicitou auxílio para a resolução da situação problema.

Cada grupo adotou um modelo de procedimento para confecção da primeira caixinha. O Grupo 1 dividiu as atividades entre seus componentes, um ficou responsável pela resolução do modelo matemático para calcular o maior volume possível da caixinha e os outros dois ficaram responsáveis pela confecção da caixinha. O Grupo 2 se dividiu com a mesma quantidade para a etapa de resolução e de confecção, em que ficaram dois responsáveis pela resolução conjunta do maior volume possível e os outros dois responsáveis pela confecção da caixinha. Por fim, o Grupo 3 dividiu as tarefas de modo parecido com o Grupo 2, a diferença ficou por conta dos dois que tentavam encontrar o maior volume possível, em que cada um fez separadamente sua resolução e confrontaram seus resultados. Chegaram a resultados divergentes e então foi solicitado o auxílio de um dos bolsistas que constatou o acerto de um deles.

Após a primeira caixinha confeccionada, foram entregues pedaços de cartolina de dimensões variadas para que pudessem testar o aprendido com outros modelos de caixinhas. Todos os grupos conseguiram confeccionar suas caixinhas sem tampa com êxito, mas não todos ao mesmo tempo, o que evidencia nos participantes a compreensão do assunto tratado no minicurso. Desse modo houve convergência com o defendido por Carvalho (2009) e Serrazina (1990), que indicam que a atividade não deve ser centrada no material, mas nas operações que se realizam sobre ele.

Durante as atividades, foi observado que surgiram dúvidas que estavam relacionadas com a confecção das caixinhas, ou seja, os questionamentos relacionados à como cortar, como colar, como montar e outras atividades diretamente ligadas com a 
Poliana Pereira Lopes, Victor Pereira Machado, Thiago Beirigo Lopes

Aplicação de cálculo diferencial na otimização de áreas e volumes com uso de materiais concretos manipuláveis

confecção das caixinhas. Os próprios integrantes dos grupos discutiam entre si sobre o melhor modo de realizar a atividade. Nesse momento, em consequência das atividades propostas, se fez presente o desenvolvimento e manifestação da criatividade que, segundo Alencar (1986), não dependem exclusivamente dos esforços do próprio indivíduo.

Com a confecção das caixinhas sem tampa, foi identificado que cada grupo fez utilização de diferentes métodos para realizar a colagem das bordas das caixas. O Grupo 2 cortou o canto inteiro da cartolina, sem deixar um espaço que permitisse a colagem de uma aba lateral em outra. Como alternativa para essa dificuldade, em seguida esse grupo utilizou um pedaço recortado da cartolina para colar e unir duas abas, como se fosse um remendo.

Já o Grupo 1 cortou as bordas das cartolinas deixando uma pequena parte para que passassem cola e grudassem na outra aba lateral da caixa. O Grupo 3 fez de modo diferente dos demais, foi feito apenas um corte na cartolina, dobrou essa parte cortada e colou a mesma parte na outra aba da caixinha. A Figura 1 mostra, respectivamente, as três estratégias utilizadas pelos Grupo 2, Grupo 1 e Grupo 3, em que as caixinhas azuis foram as primeiras a serem confeccionadas.

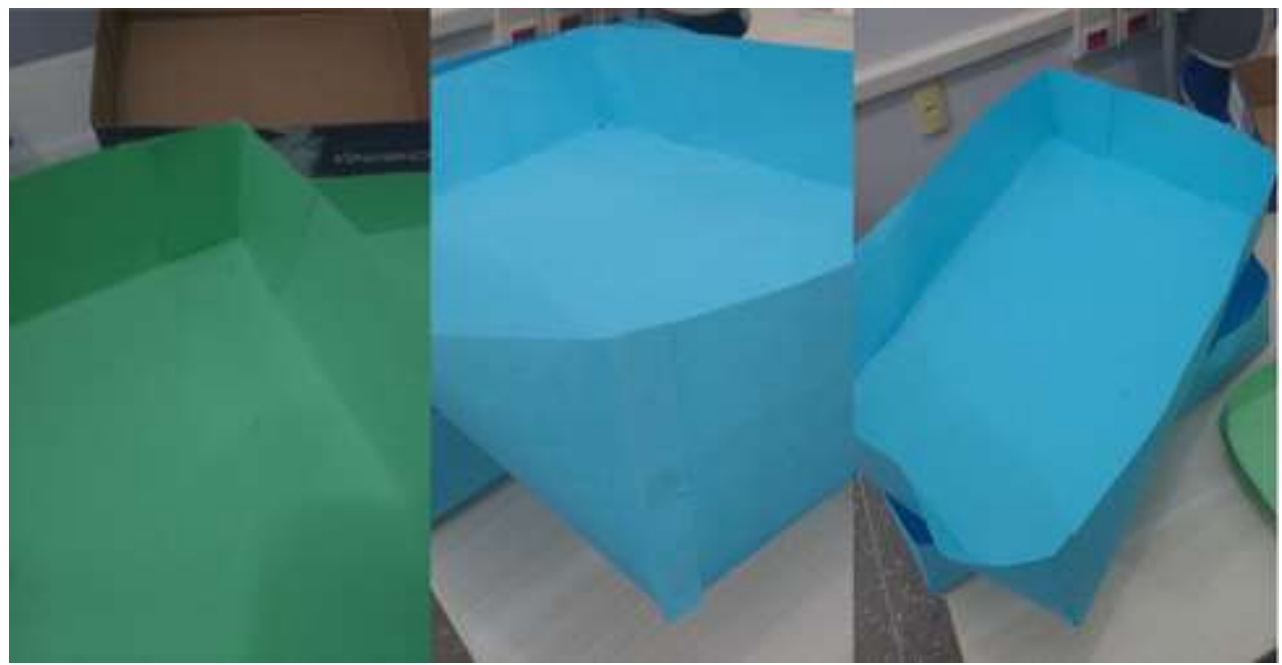

Figura 1 - Estratégias de confecção das caixinhas

Fonte: Das atividades realizadas.

Como já dito, cada grupo confeccionou três caixinhas, em que a primeira caixa de cada grupo foi construída com pedaços de cartolinas de mesmas dimensões. Os três grupos acertaram na confecção dessas primeiras caixas, uma vez que os executores do 
Poliana Pereira Lopes, Victor Pereira Machado, Thiago Beirigo Lopes

Aplicação de cálculo diferencial na otimização de áreas e volumes com uso de materiais concretos manipuláveis

minicurso conferiam os cálculos realizados pelos participantes quando solicitado. Algumas das demais caixinhas produzidas são exibidas na Figura 2.

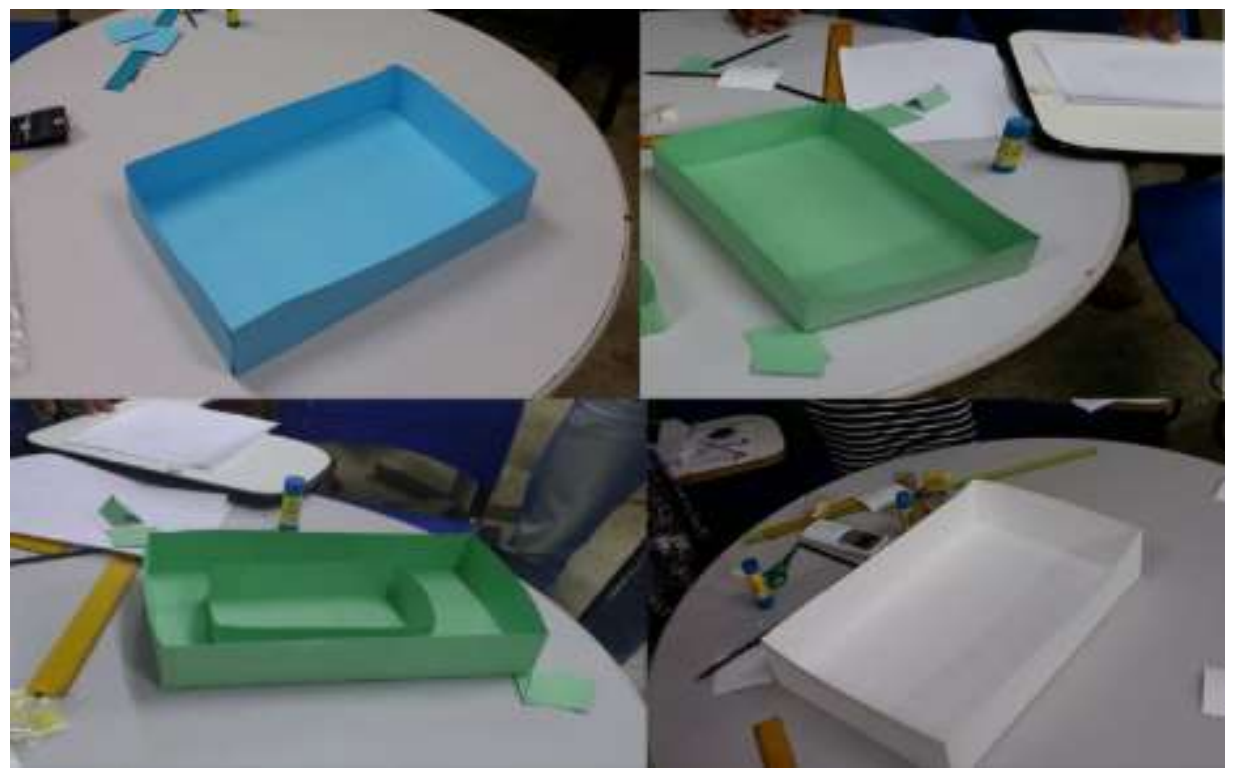

Figura 2 - Caixinhas sem tampa confeccionadas pelos estudantes

Fonte: Das atividades realizadas.

Por fim, por iniciativa própria, os grupos colocaram as três caixinhas azuis, que possuem a mesma dimensão, uma do lado da outra de modo a identificar que não havia diferença entre as três confecções.

\section{Análise das questões do questionário}

Todos os participantes responderam o questionário, assim para cada pergunta houve 11 respostas. As respostas positivas e negativas das questões 1 a 4 foram tabuladas e o resultado exposto no Erro! Fonte de referência não encontrada..

Quadro 1 - Quantitativo de respostas sim ou não nas 4 primeiras perguntas do questionário

\begin{tabular}{|c|c|c|}
\hline \multirow{2}{*}{ Questões: } & \multicolumn{2}{|c|}{ Respostas: } \\
\hline & Sim & Não \\
\hline $\begin{array}{l}\text { 1. Você já teve aulas práticas que envolvam } \\
\text { aplicações de Derivadas? }\end{array}$ & $(9,1 \%)^{1}$ & $\begin{array}{l}10 \\
(90,9 \%)\end{array}$ \\
\hline $\begin{array}{l}\text { 2. Você já havia estudado sobre aplicações } \\
\text { de derivadas em máximos e mínimos? }\end{array}$ & $\begin{array}{r}7 \\
(63,64 \%)\end{array}$ & $\begin{array}{r}4 \\
(36,36 \%)\end{array}$ \\
\hline $\begin{array}{l}\text { 3. O minicurso "Utilização de derivadas } \\
\text { para otimização de áreas e volumes" te } \\
\text { ajudou a compreender esse tipo de } \\
\text { aplicação? }\end{array}$ & $\begin{array}{r}11 \\
(100 \%)\end{array}$ & $(0 \%)^{0}$ \\
\hline $\begin{array}{l}\text { 4. Se houvessem mais estudos como o } \\
\text { deste minicurso durante as aulas de }\end{array}$ & $00 \%)$ & $\%)^{0(0}$ \\
\hline
\end{tabular}


Poliana Pereira Lopes, Victor Pereira Machado, Thiago Beirigo Lopes

Aplicação de cálculo diferencial na otimização de áreas e volumes com uso de materiais concretos manipuláveis

\begin{tabular}{|l|l|l|}
\hline cálculo diferencial, você acredita que o \\
processo de ensino e aprendizagem \\
desse conteúdo seria facilitado?
\end{tabular}

Fonte: Dos questionários aplicados.

Diante dos dados acima, cabe destacar que $90,9 \%$ dos participantes não tiveram atividades em aula que envolviam aplicações de derivadas. Mesmo que 63\% desses participantes tenham declarado terem estudado sobre máximos e mínimos. Alguns participantes que, na questão 1 , afirmaram nunca ter participado de aulas práticas de cálculo diferencial, fizeram observações sobre a resposta dada. A seguir estão dispostas as 4 respostas obtidas. Na questão 2, os participantes não fizeram observações em suas respostas sobre essa situação.

P2: "Não tive o privilégio de ter aulas práticas como neste minicurso, que ajudou muito minha compreensão”.

P3: "Não! Essa foi a primeira, mas foi bem legal, bem interessante, aprende bem, mais do que ficar só na teoria”.

P6: "Não, apenas cálculos e gráficos produzidos por programas de computador".

P7: "Não, apenas os cálculos sem entender as aplicações".

Essa situação contrasta com as indicações de Demo (1993) e de D’Ambrósio (2012) ao afirmarem que o professor precisa estimular a habilidade de raciocínio ao tornar suas aulas desafiadoras, provocativas e instigadoras. Tal fato também está em conformidade com o que indica Mello e Mello (2003) ao afirmar que o ensino de cálculo diferencial quase sempre é negligenciado pela hipotética necessidade de resolver uma infinidade de exercícios.

Outra situação que pode ser destacada é a unanimidade de que, na opinião dos participantes na questão 3 , as atividades com materiais concretos manipuláveis os levaram à compreensão de máximos e mínimos aplicados na otimização. Além disso, ainda segundo os participantes na questão 4, a utilização de atividades como a que participaram pode auxiliar o processo de ensino e aprendizagem no estudo de cálculo diferencial. 
Poliana Pereira Lopes, Victor Pereira Machado, Thiago Beirigo Lopes

Aplicação de cálculo diferencial na otimização de áreas e volumes com uso de materiais concretos manipuláveis

Na questão 3, foi confirmado que o minicurso realizado ajudou na compreensão sobre aplicação de derivada nesses casos. A seguir estão as respostas dos 4 participantes fizeram observações sobre o minicurso.

P2: "Sim, ajudou muito, pois algumas dúvidas que eu tinha foram esclarecidas".

P3: "Ajudou e muito, novos conhecimentos".

P6: "Sim, pois a parte prática juntamente com a teórica abriu a nossa mente e expandiu nosso conhecimento".

P12: "Sim, me ajudou a compreender melhor esse tipo de aplicação”.

As respostas dos 4 participantes fizeram observações sobre o minicurso. A seguir estão dispostos alguns comentários feitos nas respostas desta questão:

\section{P1: “Ajudaria muito mesmo".}

P2: "Com certeza, além de motivar bastante os estudantes a gostar mais de cálculos".

P7: "Sim, com certeza, pois desenvolvemos os cálculos e logo depois o aplicamos na prática, facilitando no entendimento”.

P12: "Sim, pois ajudaria a melhorar o processo de ensino $e$ aprendizagem".

O que contrapõe a crítica indicada por Mello e Mello (2003) e evidenciada nas respostas das questões 1 e 2 desse questionário. De certo modo, ao tratar especificamente sobre otimização, os estudos de Rocha (2013) indicam que seria interessante esses estudos serem iniciados ainda no ensino médio, o que poderia ocasionar uma maior familiaridade com esse conteúdo. Mesmo que não haja estudos em cálculo diferencial, pode-se iniciar a otimização ainda nos estudos de função quadrática.

As respostas da questão 5 foram categorizadas em Bom, Muito Bom, Ótimo e Perfeito. As categorizações foram realizadas com base nas respostas abertas obtidas no questionário, que podem ser observadas no Erro! Fonte de referência não encontrada.. 
Quadro 2 - Quantitativo de respostas na questão 5 do questionário

\begin{tabular}{|l|r|r|r|r|}
\hline \multirow{2}{*}{\multicolumn{1}{|c|}{ Questão }} & \multicolumn{4}{c|}{ Respostas: } \\
\cline { 2 - 5 } & \multicolumn{1}{|c|}{ Bom } & Muito Bom & Ótimo & Perfeito \\
\hline $\begin{array}{l}\text { 5. Como você avalia o minicurso } \\
\text { realizado? }\end{array}$ & 2 & 3 & 3 & 3 \\
& $(18,19 \%)$ & $(27,27 \%)$ & $(27,27 \%)$ & $(27,27 \%)$ \\
\hline
\end{tabular}

Fonte: Dos questionários aplicados.

Como pode ser percebido, não houve categoria que avaliassem de forma negativa o minicurso. Portanto, mesmo que as respostas não foram induzidas e dadas de modo espontâneo, pode-se considerar que a avaliação realizada pelos participantes foi positiva. A seguir, as 3 três complementações obtidas nessas respostas.

P3: "Só há a necessidade de resolver muitas contas".

P7: "Parabéns aos executores do minicurso pela ótima atividade realizada, espero sinceramente que aconteçam mais, pois hoje aprendi muito mais".

P10: "Muito produtivo e eficiente".

Por fim, fica evidente a necessidade de estratégias de ensino que envolvam métodos que estimulem e desafiem os estudantes. Confirmando o enunciado de D'Ambrósio (2012) que indica que é importante que o professor compreenda o que é a matemática, como elaborar atividades e construir um ambiente favorável para sua aprendizagem. Desse modo com vistas a promover a criatividade e possivelmente contribuir com a motivação os estudantes.

\section{Considerações Finais}

Ao considerar a experiência dos autores dessa pesquisa em anos anteriores, na qual eram evidentes as dificuldades apresentadas pelos estudantes de graduação para compreensão durante as aulas de cálculo diferencial e, mais especificamente, em máximos e mínimos em funções reais de uma variável, foi proposta essa investigação que teve como objetivo analisar se o estudo de otimização de áreas e volumes com a 
confecção de material concreto manipulável auxilia na compreensão do conceito e da aplicação desse conteúdo.

Durante a realização das atividades foi possível observar a performance dos estudantes, levando em consideração a maneira como eles resolveram as atividades, a interação que existiu entre os integrantes de cada grupo, entre os grupos, entre os participantes e os executores do minicurso, assim como dos participantes com os materiais concretos manipuláveis.

Com fundamento ainda em experiências anteriormente vivenciadas, em que o estudo de cálculo diferencial, mais especificamente de máximos e mínimos, era desenvolvido sem fazer utilização de materiais concretos manipuláveis, ficou evidente que a interatividade proporcionada pela confecção das caixinhas contribuiu para que os estudantes articulassem melhor o raciocínio matemático na busca de resolução das situações planejadas. Assim, consistiu em uma junção articuladora entre teoria e prática no ensino desse conteúdo.

No entanto, é fundamental ter consciência que quando o professor se dispõe em trabalhar com esse tipo de material didático, deve ter em mente que essa estratégia por si só não é suficiente para garantir êxito no processo de ensino e de aprendizagem. Mas essa estratégia pode contribuir de modo a possibilitar avanços significativos no desenvolvimento cognitivo nesse processo.

Desse modo, considera-se que o objetivo estabelecido por essa investigação foi atingido, pois as atividades desenvolvidas com a utilização de materiais concretos manipuláveis possibilitaram aos estudantes maior interação entre teoria e prática devido conseguirem, por meio da confecção e manuseio desses materiais, construir e analisar a otimização que anteriormente não saía das dimensões do caderno, livro ou da lousa utilizada pelo professor.

Por conseguinte, é esperado que essa investigação apresentada possa contribuir para que professores matemáticos aperfeiçoem e ampliem seus conhecimentos, compreendam que ensinar e aprender dentro da sociedade contemporânea requer a necessidade de trabalhar com inovadores métodos e metodologias de ensino. De modo a ressignificar os conteúdos e possibilitar aos estudantes utilizar as informações recebidas para suprir suas necessidades e dificuldades. 


\section{Referências}

ALENCAR, Eunice Maria Lima Soriano de. Criatividade e ensino. Psicologia: Ciência e Profissão, Brasília, v. 6, n. 1, p. 13-16, 1986. Disponível em:

<http://www.scielo.br/pdf/pcp/v6n1/04.pdf >. Acesso em: 22 jan. 2018.

ALVES, Carla; MORAIS, Carlos. Recursos de apoio ao processo de ensino e aprendizagem da matemática. In: VALE, Isabel, et al. (Org.). Números e álgebra: na aprendizagem da matemática e na formação de professores. Lisboa: Sociedade Portuguesa de Ciências da Educação, 2006. p. 335-349. Disponível em:

<https://bibliotecadigital.ipb.pt/handle/10198/1087 >. Acesso em: 21 jan. 2018.

ALVES, Eva Maria Siqueira. A ludicidade e o ensino de matemática. São Paulo: Papirus Editora, 2006.

ÁVILA, Geraldo. O ensino de Cálculo no 2. ${ }^{\circ}$ grau. Revista do Professor de Matemática, Rio de Janeiro, v. 18, 1991. Disponível em:

< http://rpm.org.br/cdrpm/18/1.htm $>$. Acesso em: 23 jan. 2018.

AYRES, Frank; MENDELSON, Elliott. Cálculo. Tradução de Adonai Schlup Sant'Ana. $5^{\text {a }}$. ed. Porto Alegre: Bookman, 2013.

AZEVEDO, Carlon Gama de. Problemas de otimização no ensino médio. 2015. $54 \mathrm{f}$. Manaus: Dissertação (Mestrado em Matemática) - Universidade Federal do Amazonas, Manaus, 2015. Disponível em: 〈http://tede.ufam.edu.br/handle/tede/4640 >. Acesso em: 25 jan. 2018.

BOTAS, Dilaila; MOREIRA, Darlinda. A utilização dos materiais didáticos nas aulas de Matemática: um estudo no $1^{\circ}$ Ciclo. Revista Portuguesa de Educação, Braga, v. 26, n. 1, p. 253-286, 2013. Disponível em:

<http://www.redalyc.org/pdf/374/37428913010.pdf >. Acesso em: 27 jan. 2018.

BOYER, Carl Benjamin. Tópicos de história da matemática para uso em sala de aula: cálculo. Tradução de Hygino H. Domingues. São Paulo: Atual, 1992.

CABRAL, Joana Filipa Oliveira. Problemas de otimização no contexto das derivadas. Lisboa. 275 f. 2015: Dissertação (Mestrado em Ensino de Matemática) Universidade de Lisboa, Lisboa, 2015. Disponível em:

<http://hdl.handle.net/10451/22707 >. Acesso em: 15 jan. 2018.

CARVALHO, Dione Lucchesi de. Metodologia do Ensino da Matemática. $3^{\text {a }}$. ed. São Paulo: Cortez, 2009.

CAVASOTTO, Marcelo. Dificuldades na aprendizagem de cálculo: o que os erros cometidos pelos alunos podem informar. 100 f. Porto Alegre: Dissertação (Mestrado em Educação em Ciências e Matemática) - Pontifícia Universidade Católica do Rio Grande do Sul, Porto Alegre, 2010. Disponível em:

<http://meriva.pucrs.br:8080/dspace/handle/10923/3000 >. Acesso em: 10 jan. 2018. 
D’AMBRÓSIO, Ubiratan. Educação matemática: da teoria à prática. $23^{\mathrm{a}}$. ed. Campinas: Papirus, 2012. (Coleção Perspectiva em Educação Matemática).

DEMO, Pedro. Desafios modernos da educação. Petrópolis: Vozes, 1993.

GRAVINA, Maria Alice; SANTAROSA, Lucila Maria Costi. Aprendizagem da matemática em ambientes informatizados. Revista Informática na Educação Teoria e Prática, Porto Alegre, v. 1, 1999. Disponível em:

<http://www.lume.ufrgs.br/handle/10183/20962 >. Acesso em: 12 jan. 2018.

GUIDORIZZI, Hamilton Luiz. Um curso de cálculo. $5^{\mathrm{a}}$. ed. Rio de Janeiro: LTC, v. 1, 2013.

LOPES, Thiago Beirigo; SANTOS, Leniedson Guedes dos. O uso do Geogebra como ferramenta auxiliar para estudo da reta tangente a um gráfico. RENOTE: Revista Novas Tecnologias na Educação, v. v. 14, n. 2, p. 1-10, 2016. Disponível em: <http://seer.ufrgs.br/index.php/renote/article/view/70637 >. Acesso em: 8 jan 2017.

MELLO, João Carlos Correia Baptista Soares de; MELLO, Maria Helena Campos Soares de. Integração entre o ensino de cálculo e o de pesquisa operacional. Revista Produção, v. 13, n. 2, p. 123-129, 2003. Disponível em:

<http://www.scielo.br/pdf/\%0D/prod/v13n2/v13n2a12.pdf >. Acesso em: 22 fev. 2018.

MUNEM, Mustafa A.; FOULIS, David J. Cálculo. Rio de Janeiro: LTC, v. 1, 1982.

NAKANO, Tatiana de Cássia. Programas de treinamento em criatividade: conhecendo as práticas e resultados. Psicologia Escolar e Educacional, v. 15, n. 2, p. 311-322, 2011. Disponível em: 〈http://www.scielo.br/pdf/pee/v15n2/v15n2a13.pdf >. Acesso em: 18 jan. 2018.

OTAVIANO, Alessandra Barbosa Nunes; ALENCAR, Eunice Maria Lima Soriano de; FUKUDA, Cláudia Cristina. Estímulo à criatividade por professores de Matemática $\mathrm{e}$ motivação do aluno. Psicologia Escolar e Educacional, Maringá, v. 16, n. 1, p. 61-69, jan/jun 2012. Disponível em: 〈http://www.scielo.br/pdf/pee/v16n1/07.pdf >. Acesso em: 19 jan. 2018.

PINTO, Rieuse Lopes. Definições matemáticas sobre funções e suas derivadas como um eixo de discussão para o ensino e a aprendizagem do cálculo. 2014. 143f. Ouro Preto: Dissertação (Mestrado em Educação Matemática) - Universidade Federal de Ouro Preto, Ouro Preto, 2014. Disponível em:

<http://repositorio.ufop.br/handle/123456789/3705 >. Acesso em: 25 jan. 2018.

ROCHA, Alan Martins. Problema de otimização envolvendo a matemática do ensino médio. 2013. 52 f. Goiânia: Dissertação (Mestrado Profissional em Matemática em Rede Nacional) - Universidade Federal de Goiás, Goiânia, 2013. Disponível em: <http://repositorio.bc.ufg.br/tede/handle/tde/2955 >. Acesso em: 21 fev. 2018. 
Poliana Pereira Lopes, Victor Pereira Machado, Thiago Beirigo Lopes

Aplicação de cálculo diferencial na otimização de áreas e volumes com uso de materiais concretos manipuláveis

RODRIGUES, Fredy Coelho; GAZIRE, Eliane Scheid. Reflexões sobre uso de material didático manipulável no ensino de matemática: da ação experimental à reflexão.

Revemat: Revista Eletrônica de Educação Matemática, Florianópolis, v. 7, n. 2, p. 187-196, dez. 2012. Disponível em:

<https://periodicos.ufsc.br/index.php/revemat/article/view/26126 >. Acesso em: 18 fev. 2018.

SERRAZINA, Lurdes. Os materiais e o ensino da Matemática. Educação e

Matemática, Lisboa, v. 13, n. 1, p. 1 (Editorial), 1990. Disponível em:

<http://www.apm.pt/files/_EM13_pp01_4d6bd9e8e8334.pdf >. Acesso em: 25 jan.

2018.

SILVA, Carlos Rodrigues da; SOUSA, Kelia Rodrigues de Queiroz. Cálculo: uma proposta possível para o ensino médio. Revista Panorâmica On-Line, Barra do Garças, v. 17, p. 81 - 89, 2014. Disponível em:

<http://revistas.cua.ufmt.br/index.php/revistapanoramica/article/viewFile/595/234 >. Acesso em: 23 jan. 2018. 